\title{
Manometric evaluation of the interdigestive antroduodenal motility in subjects with fasting bile reflux, with and without antral gastritis
}

\author{
P A TESTONI, L FANTI, F BAgNOLO, S PASSARETTI, M GUSLANDi, \\ E MASCI, AND A TITTOBELLO
}

From the Gastroenterology Unit, Institute of Internal Medicine, University of Milan, Milan, Italy

SUMMARY The interdigestive antroduodenal motor activity was studied in 15 patients with bile reflux without gastritis (group A), 17 with bile reflux and chronic antral superficial gastritis (group B) and in nine healthy controls (group C), by manometric recording of phases of the interdigestive motility complex (IDMC) over $\mathbf{2 4 0}$ minutes, or until two consecutive migrating motor complexes (MMCs) had been recorded, whichever the shorter. In the patients with bile reflux the occurrence of MMCs was decreased and median duration of the IDMC was significantly prolonged (group $A=162.5 \mathrm{~min}$; group $B=185.0 \mathrm{~min}$ ), compared with controls (group $C=92.0 \mathrm{~min} ; \mathrm{p}<0.01 v$ groups $A$ and $B)$. There were no differences in motility pattern between patients with and without gastritis, suggesting that motor abnormalities are not caused by gastritis, but may precede its occurrence. Delayed occurrence of motor activity fronts increases duodenogastric reflux, but correlation with gastric mucosal lesions was not shown, suggesting that other mechanisms are involved.

The role of antroduodenal motility in the genesis of duodenogastric reflux ${ }^{1-7}$ and chronic antral gastritis -11 is widely accepted, but few data are available at present on the possible motor abnormalities related to this phenomenon.

A recent study ${ }^{12}$ postulated a significant correlation in the fasting state between duodenogastric reflux and abnormalities of the interdigestive motility complex (IDMC), mainly characterised by a reduced incidence of migrating motor complexes (MMCs).

This study was carried out, however, in subjects without evidence of gastric mucosal damage.

While the motility disturbances of the antroduodenal region seem to play a prominent role in duodenogastric reflux, it is still debated if these abnormalities, or factors, such as the qualitative composition of bile salts in the refluxed material or the mucosal resistance, are primarily involved in the genesis of chronic antral gastritis. ${ }^{15-17}$ There is, in fact,

Address for correspondence: Pier Alberto Testoni, MD, Gastroenterology Unit, Institute of Internal Medicine, University of Milan, via Pace, 920122 , Milano, Italy.

Accepted for publication 30 October 1988 . evidence that a high amount of bile reflux may not be associated with gastric mucosal lesions. ${ }^{18}$

In order to evaluate the possible type and severity of abnormalities of the IDMC leading to chronic antral gastritis in the presence of duodenogastric reflux, we have studied and compared the interdigestive motility pattern of the antroduodenal region in subjects with proven duodenogastric reflux, with and without gastritis.

Methods

PATIENTS

Three groups of subjects were admitted to the study. The first group (group A) included 15 patients aged between 22 and 55 years (mean age, 40.5), eight men and seven women, with proven duodenogastric reflux and without endoscopic and histological evidence of gastric mucosal damage. Bile reflux, documented by the presence of a large amount of bile in the gastric fundus and of bile staining the gastric walls in the fasting state during endoscopic examination, ${ }^{19}$ was confirmed and quantified by measuring bile salt concentrations in fasting aspirates. Twelve subjects complained of chronic dyspeptic symptoms, whereas 
three were asymptomatic; in these three cases the presence of duodenogastric reflux had been found by chance during endoscopic investigation of the upper digestive tract. In the second group (group B) 17 subjects were studied. They were aged between 23 and 51 years (mean age, 41.9), 10 men and seven women, with proven duodenogastric reflux according to the above mentioned methods and with endoscopic and histological features of chronic antral superficial gastritis. All the patients in group B complained of chronic dyspeptic symptoms.

As a control group, nine healthy subjects without evidence of duodenogastric reflux, gastric mucosal damage and dyspeptic complaints were investigated (group C). The controls were matched for age (23-48 years; mean age, 40.2) and sex (five men and four women).

Control subjects and the three asymptomatic patients of group A underwent endoscopic examination in order to exclude gastric precancerous lesions during a mass screening. Biopsies and other investigational tests were performed after all the subjects admitted to the study had given their informed consent.

All the patients and controls underwent endoscopic examination with multiple biopsies (four in the antrum, four in the corpus) of gastric mucosa.

The diagnosis of chronic superficial gastritis was formulated according to Glass and Pitchumoni's histological criteria ${ }^{20}$ while endoscopic features of gastritis consisted of hyperaemia, erosions and mucosal fragility.

To avoid other causes of dyspepsia, other disorders of the upper gastrointestinal tract, gall bladder and pancreas were excluded by means of endoscopy, ultrasonography, abdominal pain $x$-ray film and laboratory tests for liver and pancreas. Subjects aged over 60 years and patients with a history of previous gastrointestinal surgery, alcoholism, diabetes, collagenous diseases and chronic liver diseases with portal hypertension were also excluded from the study, because of the possible influence of these conditions on the motility of the digestive tract.

\section{ASSESSMENT OF DUODENOGASTRIC BILE}

REFLUX

Some days after the endoscopic examination a nasogastric tube was positioned in the stomach of all the subjects under fluoroscopic control. Gastric juice was aspirated, in the fasting condition, for 60 minutes after the gastric residuum had been discarded. ${ }^{2122}$ Total bile acid concentration was determined by means of the enzymatic method of Talalay, ${ }^{23}$ and the values obtained were multiplied by the volume aspirated over 60 minutes (divided in 15 minute periods), to calculate the amount of the reflux. Only patients with a 'bile reflux' of more than $120 \mu \mathrm{mol} / \mathrm{h}$ were admitted to the study (group A: median $=337$ $\mu \mathrm{mol} / \mathrm{h}$, range, $123-502 \mu \mathrm{mol} / \mathrm{h}$; group $\mathrm{B}$ : median= $301 \mu \mathrm{mol} / \mathrm{h}$, range, $129-849 \mu \mathrm{mol} / \mathrm{h}$; not significant difference between the two groups). This arbitrary cut-off value has been selected because, as reported by Hoare $e t a l^{21}$ and Dewar and Johnston, ${ }^{22}$ it could distinguish between controls and patients with symptomatic reflux gastritis and therefore it may be considered as a reliable index of pathologic duodenogastric bile reflux. Moreover, although such a value was obtained from studies of postoperative stomachs, in our series of patients without previous gastric surgery a total bile acid concentration higher than $120 \mu \mathrm{mol} / \mathrm{h}$ was found in $80 \%$ of cases with endoscopic evidence of bile reflux (bile in the gastric fundus and bile staining the gastric walls), as already observed also in our previous studies. ${ }^{12}{ }^{13}$

In all the subjects of the control group, bile acid concentrations so low as to be unmeasurable were obtained.

\section{RECORDING OF ANTRODUODENAL MOTOR \\ ACTIVITY}

The motor activity of the antroduodenal region was investigated by manometric recording of the phases of the IDMC. After an overnight fast, a five lumen PVC probe (external diameter, $0.5 \mathrm{~cm}$ ) with five side holes $5 \mathrm{~cm}$ apart and surface radiopaque markers located in the middle between the third and the fourth hole was positioned under fluoroscopic control in the proximal part of the duodenum, by locating the radiopaque markers across the pyloric junction. The three upper recording holes were placed in the distal stomach and the two distal holes in the proximal duodenum. The probe position was also verified fluoroscopically at the end of the study. The recording catheters were perfused with distilled water $(1.2 \mathrm{ml} / \mathrm{min})$, using a pneumohydraulic low compliance pump, and were connected by five Statham P23 ID transducers to a six channel polygraph (OTE Biomedica).

Recording of the interdigestive motor activity was performed over 240 minutes, as suggested by other authors, ${ }^{24} 25$ or until two consecutive activity fronts (phase 3 of the IDMC) had been recorded. Drugs affecting gastrointestinal motility were withdrawn at least $48 \mathrm{~h}$ before the study. The following determinants of the interdigestive motility complex were evaluated: frequency and site of onset of migrating motor complexes (MMCs); mean duration of the entire cycle of IDMCs; mean duration and percentage of time recorded occupied by the single phases of the IDMC.

Statistical analysis of the data was carried out by Fisher's exact test, and Mann-Whitney U test. 


\section{Results}

GROUP A ( 15 CASES): SUBJECTS WITH DUODENOGASTRIC BILIARY REFLUX, WITHOUT EVIDENCE OF GASTRITIS

The median duration of the recording period was 240 minutes (range, 180-240 minutes). In this group only four of the 15 cases investigated $(26 \cdot 7 \%)$ showed two consecutive MMCs during the recording period; in nine subjects $(60 \%)$ only one activity front was recorded, whereas in two cases (13.3\%) no MMC was observed during the recording period prolonged to 240 minutes.

Over a total recording period of 3301 minutes, 17 MMCs were noticed, nine starting in the antrum and eight in the duodenum. In the four cases who showed two consecutive MMCs the median duration of the entire interdigestive motor cycle was 162.5 minutes (range, 159-169 minutes). Phase 1 occupied $46.2 \%$ of the IDMC (range, 44.4-47.5\%); phase 2, $46.4 \%$ (range, $41 \cdot 7-50 \cdot 0 \%$ ); and phase $3,7 \cdot 4 \%$ (range, $4 \cdot 6$ $11 \cdot 1 \%)$.

No correlation was found in this group between the occurrence and the severity of dyspeptic symptoms and the motility pattern.

GROUP B ( 17 CASES): SUBJECTS WITH DUODENOGASTRIC BILIARY REFLUX WITH EVIDENCE OF CHRONIC SUPERFICIAL GASTRITIS The median duration of the recording period in this group was 240 minutes (range, 180-240 minutes). In seven of the 17 cases investigated $(41 \cdot 2 \%)$, two consecutive MMCs were observed during the recording period; in eight subjects $(47 \%)$ only one activity front was recorded, whereas in two cases $(11 \cdot 8 \%)$ no MMC was noticed.

During a total recording period of 3607 minutes, 22 MMCs were observed, 15 starting in the antrum and seven in the duodenum. In the seven cases with two consecutive MMCs, the median duration of the IDMC was $185 \cdot 0$ minutes (range, 71-215 minutes).
Phase 1 occupied $45 \cdot 1 \%$ of the IDMC (range, $38 \cdot 0$ $58 \cdot 3 \%$ ); phase $2,49 \cdot 3 \%$ (range, $34 \cdot 5-57.2 \%$ ); and phase $3,5 \cdot 6 \%$ (range, $3 \cdot 1-10 \cdot 7 \%$ ).

GROUPC (NINE CASES): CONTROL SUBJECTS, WITHOUT EVIDENCE OF DUODENOGASTRIC BILIARY REFLUX AND GASTRIC MUCOSAL

DAMAGE

The median duration of the recording period in this control group was 180 minutes (range, 86-240 minutes). All but one subject (eight cases $=88.9 \%$ ) showed regular IDMC; in the remaining case only one MMC was observed in 240 minutes.

Over a recording period of 1514 minutes, 17 MMCs were noticed, 13 starting in the antrum and four in the duodenum. In the eight subjects who showed two consecutive MMCs, the median duration of the IDMC was 92.0 minutes (range 67-112 minutes). Phase 1 occupied $46.5 \%$ of the IDMC (range, 27.9-74.4\%); phase 2, 47.2 (range, 11.6$67 \cdot 9 \%$ ); and phase $3,6 \cdot 3 \%$ (range, $2 \cdot 7-8 \cdot 3 \%$ ).

A considerable reduction in the frequency of phase 3 of the IDMC and in the occurrence of two consecutive MMCs was observed in subjects with duodenogastric bile reflux (groups $\mathrm{A}$ and $\mathrm{B}$ ), in comparison with controls (group C). In fact the number of subjects showing only one MMC or complete absence of activity fronts appeared significantly higher in groups $\mathrm{A}$ and $\mathrm{B}$ than in the control group (group A $v$ group $\mathrm{C}, \mathrm{p}<0.005$; group $\mathrm{B} v$ group $C, p<0 \cdot 025$; Fisher's exact test), whereas no differences were found between groups A and B (Table 1). Likewise, no correlation was detected in groups $\mathrm{A}$ and $\mathrm{B}$ between intragastric bile acid concentration and antro duodenal motility disorders.

Moreover, no important differences were detected between the three groups as to the site of onset of MMCs and the percentage of time occupied by each phase of the IDMC (Fisher's exact test) (Table 1 and 2).

The median duration of the IDMC appeared to be

Table 1 Percentage of time recorded occupied by the single phases of the IDMC and number of MMC recorded in subjects of the three groups

\begin{tabular}{|c|c|c|c|c|c|c|c|c|c|c|}
\hline \multirow[b]{2}{*}{ Groups } & \multirow[b]{2}{*}{$\begin{array}{l}\text { Subjects } \\
(n)\end{array}$} & \multirow[b]{2}{*}{$\begin{array}{l}\text { Recording } \\
\text { period }^{*}(\text { min })\end{array}$} & \multicolumn{2}{|l|}{ Phase 1} & \multicolumn{2}{|l|}{ Phase 2} & \multicolumn{2}{|l|}{ Phase 3} & \multicolumn{2}{|c|}{$\begin{array}{l}\text { Subjects in whom } \\
\text { were recorded }\end{array}$} \\
\hline & & & $\begin{array}{l}\text { Time } \\
\text { recorded } \\
(\%)\end{array}$ & $\begin{array}{l}\text { Range } \\
(\%)\end{array}$ & $\begin{array}{l}\text { Time } \\
\text { recorded } \\
(\%)\end{array}$ & $\begin{array}{l}\text { Range } \\
(\%)\end{array}$ & $\begin{array}{l}\text { Time } \\
\text { recorded } \\
(\%)\end{array}$ & $\begin{array}{l}\text { Range } \\
(\%)\end{array}$ & $2 M M C s$ & $\begin{array}{l}1 \text { orno } \\
M M C\end{array}$ \\
\hline A & 15 & $240(180-240)$ & $46 \cdot 2$ & $44 \cdot 4-47 \cdot 5$ & $46 \cdot 4$ & $41 \cdot 7-50 \cdot 0$ & $7 \cdot 4$ & $4 \cdot 6-11 \cdot 1$ & $4 \dagger$ & $11 \dagger$ \\
\hline B & 17 & $240(180-240)$ & $45 \cdot 1$ & $38 \cdot 0-58 \cdot 3$ & $49 \cdot 3$ & $34 \cdot 5-57 \cdot 2$ & $5 \cdot 6$ & $3 \cdot 1-10 \cdot 7$ & $7 \ddagger$ & $10 \ddagger$ \\
\hline C & 9 & $180(86-240)$ & $46 \cdot 5$ & $27 \cdot 9-74 \cdot 4$ & $47 \cdot 2$ & $11 \cdot 6-67 \cdot 9$ & $6 \cdot 3$ & $2 \cdot 7-8 \cdot 3$ & 8 & 1 \\
\hline
\end{tabular}

$\mathrm{A}=$ subjects with duodenogastric biliary reflux, without gastritis; $\mathrm{B}=$ subjects with duodenogastric biliary reflux, with evidence of chronic superficial gastritis; $C=$ control subjects. *median and range; $\nmid p<0.005$ in comparison with control group, not significant if compared with group $B ; \neq p<0.025$ in comparison with control group. 
Table 2 Number of MMCs observed during overall period of recording and site of onset

\begin{tabular}{|c|c|c|c|c|}
\hline \multirow[b]{2}{*}{ Groups } & \multirow{2}{*}{$\begin{array}{l}\text { Overall } \\
\text { recording } \\
\text { period (min) }\end{array}$} & \multirow{2}{*}{$\begin{array}{l}\text { MMCs } \\
\text { recorded }\end{array}$} & \multicolumn{2}{|c|}{ Site of onset of $M M C s$} \\
\hline & & & Stomach & Duodenum \\
\hline A & 3301 & 17 & $952.9 \%$ & $847 \cdot 1 \%$ \\
\hline B & 3607 & 22 & $1568 \cdot 2 \%$ & $731.8 \%$ \\
\hline $\mathrm{C}$ & 1514 & 17 & $1376 \cdot 5 \%$ & $423 \cdot 5 \%$ \\
\hline
\end{tabular}

Group $\mathrm{A}=$ subjects with duodenogastric bile reflux, without gastritis; Group $B=$ subjects with duodenogastric bile reflux, with evidence of chronic superficial gastritis: Group $\mathrm{C}=$ control subjects.

significantly increased $(p<0 \cdot 01)$ in subjects of group $\mathrm{A}$ and in subjects of group B, compared with controls (Figure), while no differences were observed

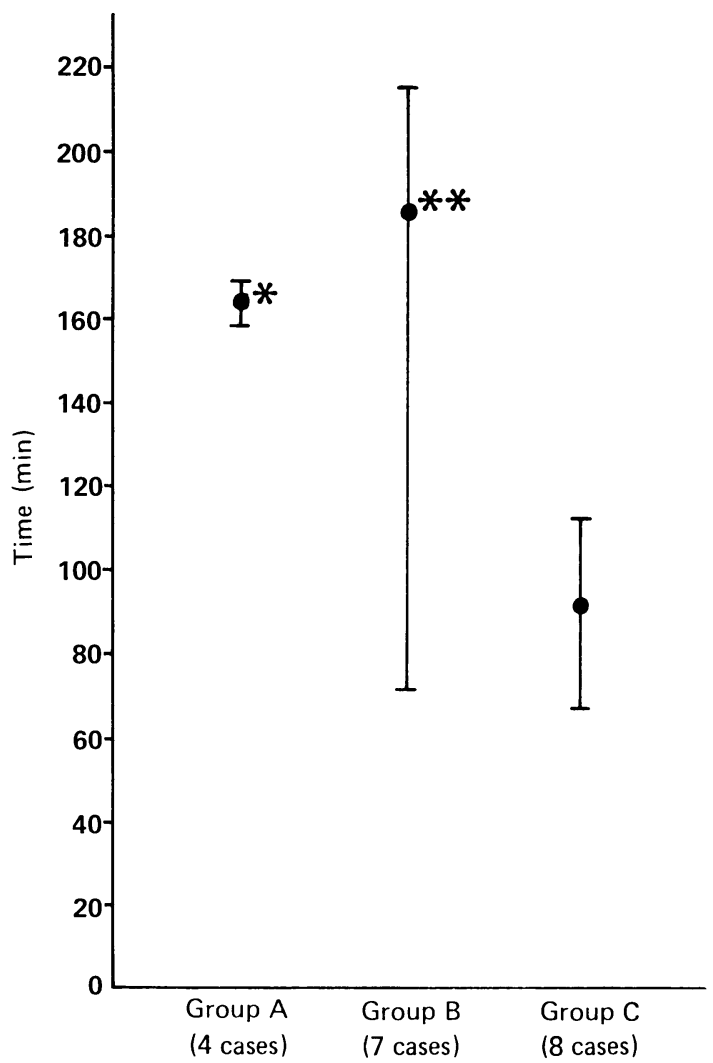

Figure Median duration of the interdigestive motility complex (IDMC) in minutes, in subjects with two consecutive MMCs. Group A=subjects with duodenogastric bile reflux, without gastritis; group $B=$ subjects with duodenogastric bile reflux, with evidence of chronic superficial gastritis; group $C=$ control subjects. Vertical bars represent the range of variability. ${ }^{*} p<0.01$ in comparison with control subjects; NS if compared with group B; $*^{* *} p<0.01$ in comparison with control subjects. between the two groups of subjects with biliary reflux (group A $v$ group B). Because of the small number of available data, which did not show a normal distribution, non-parametric statistics - that is, MannWhitney U test - were used in this evaluation.

\section{Discussion}

Among the factors involved in the genesis of chronic antral gastritis, the antroduodenal motility, the damaging activity of the refluxed material and the gastric mucosal defences are generally believed to play a primary role, either as single, or as associated factors.

There is evidence that antroduodenal motor disorders are related on the one hand to an increased duodenogastric bile reflux, ${ }^{12}$ and on the other hand to a reduced clearing capacity of the antral region, ${ }^{626}$ with prolonged contact in the fasting state between the refluxed duodenal content and the gastric mucosa..$^{x-1027}$

In particular, it has been observed that phase 3 (migrating motor complex) of the interdigestive motility complex is able to prevent duodenogastric reflux and to clear the antral region in the fasting state of refluxed material. ${ }^{26}$ These two mechanisms are in fact able to significantly reduce the intragastric volume of refluxed bile, that is highest during late phase 2 and lowest in phase 3 . A prolonged duration of phase 2 may therefore be postulated in the presence of abnormal bile reflux.

In this regard, however, conflicting data are reported about the correlation between motor abnormalities and antral gastritis; a decreased motor activity, with delayed occurrence of MMCs, has been demonstrated only to be associated with abnormal duodenogastric reflux.

Moreover, whether motility disorders are a cause or a consequence of antral gastritis is still debated and needs further investigation.

It has also been reported ${ }^{13}$ that the relative increase in the concentration of deoxycholic acid and its tauroconjugates in the refluxed bile may be a factor leading to the onset and persistence of mucosal lesions, independently of motor abnormalities, and this has been associated with chronic superficial gastritis and with chronic atrophic gastritis. In the same study, ${ }^{13}$ the composition of mucus (as assessed by means of the Mucoprotective Index) was found within normal values in cases of chronic superficial gastritis, and in presence of duodenogastric bile reflux with normal gastric mucosa, as observed in healthy controls. Therefore, it seems that mucus composition is not primarily involved in the pathogenesis of chronic superficial gastritis.

On the basis of these previous observations, it may 
be expected that, in presence of biliary reflux, evidence of chronic superficial gastritis should be associated with more severe abnormalities of the IDMC (prolongation of the entire IDMC and of phase 2, and/or alterations of the site of onset of MMCs), in comparison with refluxers without gastritis and controls.

In fact, in our study, a significant increase in the duration of the interdigestive motility complex (IDMC) with subsequent reduction of the frequency of MMCs during the recording period of 240 minutes, has been observed in all patients with duodenogastric reflux, in comparison with controls, regardless of the presence or absence of gastritis.

On the other hand, no difference has been observed among the two groups of refluxers with and without gastritis, suggesting that other factors may be involved in the genesis of chronic mucosal inflammation, in addition to motility disorders of the antroduodenal region. In this regard, in our study no correlation was found in groups A and B between intragastric bile acid concentration and severity of antroduodenal motor abnormalities, even though, because of the small number of cases included, further investigation would be required to draw definitive conclusions. Finally, no difference has been observed in the three groups regarding the duration of the phase 2 of the IDMC and the site of onset of MMCs (stomach or duodenum).

The significance of absence or reduction of the phase 3 of the IDMC in the antral region is unknown; we cannot exclude that a more prolonged period of observation would show the presence of activity fronts, as their frequency seems rather variable..$^{28}$ There is, however, a general agreement that most normal subjects show at least two consecutive MMCs during a recording period of 240 minutes, ${ }^{242529}$ although in some cases a marked reduction or absence of MMCs has been described. ${ }^{6}$ It is also difficult to establish possible abnormalities in the motility pattern of humans, as a great variability in the interdigestive motor complexes has been reported in healthy individuals; on the other hand whether duodenogastric reflux is pathological or not it is still debated.

The multilumen probe inserted across the pylorus in the duodenum might be responsible of possible changes in the antro duodenal motility. Previous investigations have suggested, however, that the catheter does not significantly affect this motility pattern. ${ }^{30}$

In conclusion, our findings suggest that: (a) the strict relationship observed between the presence of duodenogastric reflux and the reduced occurrence of phase 3 of the IDMC confirms our previous findings on the primary role of migrating motor complex
(MMC) in the prevention of biliary reflux; (b) no difference in the motor abnormalities has been found, among the cases with bile reflux, in subjects with and without gastritis; further investigations are required in order to evaluate the significance of the clearing interdigestive capacity of the refluxed material by the IDMC, as this mechanism, which was believed to be involved as a possible cause of gastritis, does not seem a determinant factor in our study: (c) motor abnormalities are only partially involved in the pathogenesis of gastritis, in that they increase the frequency and amount of duodenogastric reflux, but other factors would actually induce the mucosal damage. Among the different factors involved, our previous studies suggest that a prominent role can be attributed to the qualitative composition of bile salts, whereas mucus composition was found not to differ between patients with mild gastritis and controls; (d) the motility disorders of the antroduodenal region seem to precede and not to follow the occurrence of mucosal damage. In fact, such motor disorders have also been observed in cases without gastritis, suggesting that they appear before the onset of chronic gastric mucosal lesions. A prospective study should be carried out, however, to confirm this hypothesis.

\section{References}

1 Wormsley RG. Aspects of duodenogastric reflux in man. Gut 1972; 13: 243-50.

2 Miranda M, Defilippi C, Valenzuela JE. Abnormalities of interdigestive motility complex and increased duodenogastric reflux in gastric ulcer patients. Dig Dis Sci 1985; 30: 16-21.

3 Mueller-Lissner SA, Schottenmann G, Schenker G, et al. Duodenogastric reflux in the fasting dog: role of pylorus and duodenal motility. Am J Physiol 1981; 241: $159-62$.

4 Rees WDN, Go VLW, Malagelada JR. Simultaneous measurement of antro-duodenal motility, gastric emptying and duodenogastric reflux in man. Gut 1979; 20: 96370 .

5 Keane FB, Di Magno EP, Malagelada JR. Role of the migrating motor complex (MMC) and its secretory counterpart on duodenogastric reflux in man. Gastroenterology 1980; 78: 1192.

6 Keane FB, Di Magno EP, Malagelada JR. Duodenogastric reflux in humans: its relationship to fasting antroduodenal motility and gastric, pancreatic and biliary secretion. Gastroenterology 1981; 81: 726-31.

7 Ehrlein HJ. Gastric and duodenal motility in relation to duodenogastric reflux in healthy dogs. Scand $J$ Gastroenterol 1981; 16 [suppl 67]: 23-7.

8 Cheng J, Ritchie WPJ, Delaney JP. Atrophic gastritis: an experimental model. Fed Proc 1969; $28: 513$.

9 Robbins PL, Broodie TA, Sosin H, Delaney JP. Reflux gastritis: the consequence of intestinal juice in the stomach. Am J Surg 1976; 131: 23-9. 
10 Davidson ED, Hersh T. Bile reflux gastritis. Contribution of inadequate gastric emptying. Am J Surg 1975; 130: $514-8$.

11 Cheli R, Giacosa A, Molinari F. Chronic atrophic gastritis and duodenogastric reflux. Scand $J$ Gastroenterol 1981; 16 [suppl 67]: 125-7.

12 Testoni PA, Fanti L, Passaretti S, Masci E, Guslandi M, Tittobello A. Interdigestive motility pattern in subjects with duodenogastric bile reflux. Scand J Gastroenterol 1987; 22: 757-62.

13 Masci E, Testoni PA, Fanti L, Guslandi M, Zuin M, Tittobello A. Duodenogastric reflux: correlations among bile acid pattern, mucus secretion, and mucosal damage. Scand J Gastroenterol 1987; 22: 308-12.

14 Black RB, Hole D, Rhodes J. Bile damage to the gastric mucosal barrier: the influence of the $\mathrm{pH}$ and bile acid concentration. Gastroenterology 1971; 61: 178-84.

15 Harmon JW, Doong T, Gadacz TR. Bile acids are not equally damaging to the gastric mucosa. Surgery 1978; 84: 79-86.

16 Ritchie WP, Felger TS. Differing ulcerogenic potential of dihydroxy- and trihydroxy-bile acids in canine gastric mucosa. Surgery 1981; 89: 342-7.

17 Black RB, Naylor FF, Stenhouse NS. Gastric mucosal damage by taurine and glycine conjugates of chenodeoxycholic acid. Dig Dis Sci 1977; 22: 1106-8.

18 Fisher RS. Gastroduodenal motility disturbances in man. Scand J Gastroenterol 1985; 20 [suppl 109]: 59-68.

19 Niemela S. Duodenogastric reflux in patients with upper abdominal complaints or gastric ulcer. Scand $J$ Gastroenterol 1985; 20 [suppl 115]: 1-56.

20 Glass GBJ, Pitchumoni CS. Atrophic gastritis. Hum Pathol 1975; 6: 219-50.

21 Hoare AM, Keighley MRB, Storkey B, AlexanderWilliams $\mathbf{J}$. Measurement of bile acids in fasting gastric aspirates: an objective test for bile reflux after gastric surgery. Gut 1978; 19: 166-9.

22 Dewar P, Johnston D. Bile acid and lysolecithin concentration in the stomach in patients with duodenal ulcer before operation and after treatment by highly selective vagotomy, partial gastrectomy or troncular vagotomy and drainage. Gut 1982; 23: 569-77.

23 Talalay P. Enzymic analysis of steroid hormones. Meth Biochem Anal 1960; 8: 119-43.

24 Vantrappen G, Janssens J, Hellemans J, Ghoos Y. The interdigestive motor complex of normal subjects and patients with bacterial overgrowth of the small intestine. J Clin Invest 1977; 59: 1158-66.

25 Labò G, Bortolotti M, Vezzadini P, Bonora G, Bersani G. Interdigestive gastroduodenal motility and serum motilin levels in patients with idiopathic delay in gastric emptying. Gastroenterology 1986; 90: 20-6.

26 Code CF, Schlegel JF. The gastrointestinal interdigestive housekeeper: motor correlates of the interdigestive myoelectric complex of the dog. In: Daniel EE, ed. Proceedings of the Fourth International Symposium on gastrointestinal motility. Vancouver: Mitchell Press, 1973: 631-3.

27 Brooks WS, Wenger J, Hersh T. Bile reflux gastritis. Analysis of fasting and post-prandial gastric aspirates. Am J Gastroenterol 1975; 64: 286-91.

28 Thompson DG, Wingate DL, Archer L, Benson MJ, Green WJ, Hondy RJ. Normal patterns of human upper small bowel motor activity recorded by prolonged radiotelemetry. Gut 1980; 21: 500-6.

29 Rhodes J, Barnardo DE, Phillips JF, Ravelstad RA, Hofmann AF. Increased reflux of bile into the stomach in patients with gastric ulcer. Gastroenterology 1969; 57: 214-52.

30 Larsen S, Osnes $\mathrm{M}$. The unstimulated duodenal pressure activity in healthy humans. Scand $J$ Gastroenterol 1987; 2 [suppl 131]: 1-36. 